\title{
IVF Efficiency After Metroplasty in Patients with Uterine SCAR
}

\author{
Iskakov S.S', Ibragimov A. K² and Shegenov G. $A^{1}$ \\ ${ }^{1}$ Department of Obstetrics and Gynecology №2 of the NJSC \\ "Astana Medical University", Nur-Sultan, Kazakhstan \\ ${ }^{2}$ Director of the "Ecomed" Medical Center, Nur-Sultan, Kazakhstan
}

\section{ABSTRACT}

Infertile marriage, the frequency of which does not tend to decrease, is an urgent issue of modern healthcare. According to world statistics, the frequency of infertility is $10-15 \%$ and its causes are numerous. The prevalence of this problem is increasing every year. Today, assisted reproductive technologies can help overcome all known causes of infertility. Pregnancy achieved with the use of assisted reproductive technologies ended in live births based on embryo transfer in IVF cycles 28.0\% and with ICSI 25.7\%. increasing the efficiency of assisted reproductive technologies in the treatment of uterine scar. In our study, the age of the patients, gynecological status, duration of infertility, clinical manifestations, IVF performance, results of ultrasound diagnostics for the viability of the uterine scar, as well as signs of inconsistency of the uterine scar were noted. In our study, after confirming the inconsistency of the uterine scar, 30 patients underwent metroplasty. According to the protocol, after the surgery, the patients were prescribed contraception in order to avoid unwanted pregnancy until the full recovery of the uterine scar within 6 months. Conducting pregravid metroplasty in patients with inconsistent uterine scar will significantly increase the rate of IVF success. The results obtained contributed to the introduction of metroplasty surgery to correct the inconsistency of the uterine scar in patients when planning ART.

KEY WORDS: INFERTILE MARRIAGE, IVF, METROPLASTY, SCAR.

\section{INTRODUCTION}

Infertile marriage, the frequency of which does not tend to decrease, is an urgent issue of modern healthcare. According to world statistics, the frequency of infertility is $10-15 \%$. The prevalence of this problem is increasing every year. Today, assisted reproductive technologies can help to overcome all known causes of infertility. These

\section{ARTICLE INFORMATION}

Received 13th Oct 2020 Accepted after revision 27th Dec 2020 Print ISSN: 0974-6455 Online ISSN: 2321-4007 CODEN: BBRCBA

Thomson Reuters ISI Web of Science Clarivate Analytics USA and Crossref Indexed Journal

\section{Clarivate
Analytics}

NAAS Journal Score 2020 (4.31)

A Society of Science and Nature Publication,

Bhopal India 2020. All rights reserved.

Online Contents Available at: http//www.bbrc.in/

Doi: http://dx.doi.org/10.21786/bbrc/13.15/52 methods include the transfer of gametes into the lumen of fallopian tubes, in vitro fertilization and transfer of embryos into the uterine cavity, transfer of zygotes into the lumen of fallopian tubes, transfer of embryos into fallopian tubes, freezing of gametes, and embryos, ovarian and testicular tissue, oocyte and embryo donation, surrogacy. However, the methods of assisted reproductive technologies, despite the development of technologies, demonstrate insufficient efficiency. According to ESHRE, the Russian School of Reproductology, modern ART methods can achieve the effectiveness of infertility treatment up to 30-40\% per attempt. Pregnancy achieved with the use of assisted reproductive technologies ended in live births based on embryo transfer in IVF cycles $28.0 \%$ and with ICSI $25.7 \%$.

In recent years, there has been a significant increase in cesarean section operations, the frequency of which 
exceeds the WHO recommended limit, 15\% of the volume of all delivery operations. According to the statistical collections "Health of the population of the Republic of Kazakhstan in 2018”, in the Republic of Kazakhstan in 2017 the frequency of cesarean section of the total number of women in labor was 18.6\%, in 2018 - 19.3\%. Moreover, among re-pregnant women who had a pregnancy through assisted reproductive technologies (IVF), the proportion of patients with a scar on the uterus can be up to $70-80 \%$.

Despite the fact that there is no generally accepted opinion about the possibility of the influence of the presence of a scar on the uterus on the effectiveness of IVF and on fertility in general, based on the results of a retrospective analysis, Wang Y-q. with co-authors noted a decrease in the frequency of pregnancy with the use of assisted reproductive technologies in women with a history of operative delivery. Moreover, it was found that in the presence of a scar defect on the uterus, the incidence of clinical pregnancy decreased to $12.5 \%$. In addition, the fact that a scar on the uterus poses a high risk of pregnancy complications is beyond doubt. Therefore, a thorough assessment of predictors of the effectiveness and safety of IVF procedure in patients with uterine scar requires study.

Aim of the study: increasing the efficiency of assisted reproductive technologies in the treatment of uterine scar.

\section{MATERIAL AND METHODS}

This research work was carried out from 2017 to 2020 on the basis of the Department of Obstetrics and Gynecology of the NJSC "Astana Medical University", the "Ecomed" medical center and the Akmola Regional Hospital No2 in Nur-Sultan. The first stage included an analysis of the records of patients who underwent ART from 2017-2020 in order to determine predictors of IVF performance, which included:

- $\quad$ age - 25 - 40 years;

- patients with secondary infertility who have undergone IVF treatment and transfer of one embryo (blastocyst) into the uterine cavity;

- normal menstrual function;

- $\quad$ satisfactory ovarian reserve (AMH more than $1 \mathrm{ng} /$ $\mathrm{ml}$, the total number of antral follicles in the ovaries on days 2-5 of the menstrual cycle is 6 or more)

- $\quad$ sex life in marriage;

- lack of bad habits.

Ultrasound examination of the small pelvis was carried out to assess the viability of the uterine scar in all patients with uterine scars on a Voluson S8 apparatus (General Electric, USA), with a contact scanning system using a transabdominal convex probe with a frequency of 2-5 MHz and a transvaginal probe with a frequency of $2.9-9.7 \mathrm{MHz}$, in 2D, 3D, 4D mode, allowing using longitudinal and transverse sections to assess the structure of the myometrium, the presence, and features of signs characteristic of the inferiority of the scar on the uterus. In this case, ultrasound examination was carried out in phase 1 at $5-6,8-9,12-13$, and in the second phase at 16-18 days of the menstrual cycle. A total of 804 ultrasound examinations were carried out. The main diagnostic criteria were the following:

- typical location of the scar;

- absence of deformations;

- "niches", areas of retraction;

- thickness of the myometrium in the lower uterine segment over $4 \mathrm{~mm}$;

- absence of heterogeneous inclusions in the area of the scar;

- adequate blood flow with an even distribution of color signals.

\begin{tabular}{|c|c|c|c|c|}
\hline & & $\begin{array}{l}\text { All patients } \\
(n=1858)\end{array}$ & $\begin{array}{l}\text { Patients withoutscar } \\
\text { on uterus (1657) }\end{array}$ & $\begin{array}{l}\text { Patients with scar } \\
\text { on uterus (n-201) }\end{array}$ \\
\hline & & abs \pm CI $/ \%$ & $\mathrm{abs} \pm \mathrm{CI} / \%$ & $\mathrm{abs} \pm \mathrm{CI} / \%$ \\
\hline \multirow[t]{7}{*}{ Age } & \multirow{3}{*}{$25-30$} & & & \\
\hline & & $520 \pm 0,35$ & $472 \pm 0,47$ & $48 \pm 1,48$ \\
\hline & & $(28,0 \%)$ & $(28,5 \%)$ & $(23,9 \%)$ \\
\hline & \multirow[t]{2}{*}{$31-35$} & $475 \pm 0,42$ & $404 \pm 0,51$ & $71 \pm 1,32$ \\
\hline & & $(25,6 \%)$ & $(24,4 \%)$ & $(35,3 \%)$ \\
\hline & \multirow[t]{2}{*}{$36-40$} & $863 \pm 0,97$ & $781 \pm 0,42$ & $82 \pm 1,14$ \\
\hline & & $(46,4 \%)$ & $(47,1 \%)$ & $(40,8 \%)$ \\
\hline
\end{tabular}

If signs of a defective scar on the uterus were detected, the patients underwent hysteroscopy on the 6-7th day of menstrual cycle with direct visualization of the uterine cavity using a KARLSTORZ office hysteroscope with a diameter of $5 \mathrm{~mm}$, which allows it to be inserted into the cervical canal atraumatically. At the same time, important diagnostic signs of the inferiority of the scar on the uterus include retraction in the area of the scar, whitish color 
of the scar tissue, absence of endometrium in the defect zone, depletion of the vascular pattern. A total of 38 hysteroscopic examinations were performed.

\section{RESULTS}

In accordance with the study design, the questionnaires of 1858 patients who underwent ART from 2017 to 2020 were analyzed. The age of women varied from 25 to 40 years, the average age was $36 \pm 3.1$ years. Based on the questionnaire survey and analysis of accounting and reporting documentation, all patients were divided into the following age groups and study groups (Table 1).

As can be seen from the presented table 1, the largest number of patients were in the age group from 36 to 40 years old $-46.4 \%$, in contrast to the groups $25-30$ years old and 31-35 years old, where $28 \%$ and $25.6 \%$ of patients corresponded. Analysis of gynecological diseases showed the presence of background cervical pathology, minor forms of genital endometriosis, uterine fibroids in every 6 patients [18]. At the same time, the frequency of gynecological pathology in patients with a scar on the uterus was 33.3\% (67 patients), and without a scar was $33.4 \%$ (553) patients.

Thus, $201(86.6 \%)$ patients underwent surgery on the uterus. At the same time, in 94\% (189) cases, surgical interventions were due to cesarean section, and in $6 \%$ of cases (12) due to myomectomies. In this regard, in 94\% (189) cases, the surgical approach was laparotomic, and in 6\% (12) cases, laparoscopic. During the questioning process, secondary infertility of varying duration was noted. In most patients, the duration of infertility was 4 years - 1040 patients $(56 \%)$, on average $4 \pm 1.1$ years. When analyzing the duration of infertility in patients without a scar on the uterus was 4 years - $56.1 \%$, as well as in patients with a scar on the uterus $55.2 \%$. At the same time, patients with a scar on the uterus did not have a single case with a duration of infertility for 1 year.

Table 2. Distribution of patients depending on the duration of infertility (abs / (\%))

\begin{tabular}{|c|c|c|c|c|c|c|}
\hline \multirow[t]{2}{*}{$\begin{array}{l}\text { Duration of } \\
\text { infertility }\end{array}$} & \multicolumn{2}{|c|}{ All patients (n=l858) } & \multicolumn{2}{|c|}{$\begin{array}{l}\text { Patients without the } \\
\text { scar on } \\
\text { uterus(1657) }\end{array}$} & \multicolumn{2}{|c|}{$\begin{array}{c}\text { Patients with the scar } \\
\text { on uterus (n-201) }\end{array}$} \\
\hline & abs $/ \%$ & $\pm \mathrm{CI}$ & abs $/ \%$ & $\pm \mathrm{CI}$ & abs $/ \%$ & $\pm \mathrm{CI}$ \\
\hline 1 year & $\begin{array}{c}20 \\
(1,1 \%)\end{array}$ & $\pm 3,8$ & $\begin{array}{c}20 \\
(1,2 \%)\end{array}$ & $\pm 3,8$ & $0(0 \%)$ & 0 \\
\hline 2 years & $\begin{array}{c}91 \\
(4,9 \%)\end{array}$ & $\pm 3,1$ & $\begin{array}{c}86 \\
(5,2 \%)\end{array}$ & $\pm 3,1$ & $\begin{array}{c}5 \\
(2,5 \%)\end{array}$ & $\pm 4,2$ \\
\hline 3 years & $\begin{array}{l}465 \\
(25 \%)\end{array}$ & $\pm 2,4$ & $\begin{array}{c}398 \\
(24,0 \%)\end{array}$ & $\pm 2,6$ & $\begin{array}{c}67 \\
(33,3 \%)\end{array}$ & $\pm 3,4$ \\
\hline 4 years & $\begin{array}{c}1040 \\
(56 \%)\end{array}$ & $\pm 0,84$ & $\begin{array}{c}929 \\
(56,1 \%)\end{array}$ & $\pm 1,6$ & $\begin{array}{c}111 \\
(55,2 \%)\end{array}$ & $\pm 2,6$ \\
\hline 5 years and more & $\begin{array}{c}242 \\
(13 \%)\end{array}$ & $\pm 2,7$ & $\begin{array}{c}224 \\
(13,5 \%)\end{array}$ & $\pm 2,4$ & $\begin{array}{c}18 \\
(9 \%)\end{array}$ & $\pm 4,4$ \\
\hline
\end{tabular}

Table 3. The effectiveness of IVF in the studied patients.

\begin{tabular}{|c|c|c|c|c|c|c|c|c|c|}
\hline \multirow[t]{2}{*}{ Year } & \multicolumn{3}{|c|}{ All patients (n=1858) } & \multicolumn{3}{|c|}{$\begin{array}{l}\text { Patients without the scar on } \\
\text { uterus }(1657)\end{array}$} & \multicolumn{3}{|c|}{ Patients with the scar on uterus (n-201) } \\
\hline & 1 & 2 & 3 & 1 & 2 & 3 & 1 & 2 & 3 \\
\hline 2017 & 483 & 223 & 46 & 444 & 211 & 47 & 39 & 12 & $31^{*}$ \\
\hline 2018 & 639 & 250 & 39 & 587 & 232 & 40 & 52 & 18 & $35^{*}$ \\
\hline 2019 & 736 & 356 & 48 & 626 & 321 & 51 & 110 & 35 & $32^{*}$ \\
\hline \multicolumn{10}{|c|}{${ }^{*} \mathrm{p}<0,05$} \\
\hline & & & & $\begin{array}{l}\text { mber of } \\
2 \text { - the }\end{array}$ & $\begin{array}{l}\text { transf } \\
\text { of clin } \\
\text { inical } p\end{array}$ & $\begin{array}{l}\text { he ute } \\
\text { nancie } \\
\text { es }\end{array}$ & & & \\
\hline
\end{tabular}

In a comparative analysis of the frequency of gynecological pathology in patients with and without a scar on the uterus, no statistically significant differences were found ( $\mathrm{x} 2$ = 3.905; $\mathrm{p}>0.05)$. In addition, 12.5\% (232) of patients underwent surgery on the pelvic organs. Moreover, 85.8\% (199) patients had laparotomic access and $14.2 \%$ (33) laparoscopic access. The studied patients underwent the following surgical interventions: 189 $(81.5 \%)$ - cesarean section, 17 (7.3\%) - cystectomy, 12 (5.2\%) - myomectomy, $14(6.0 \%)$ - tubectomy.
The main complaint of the treatment of the studied patients was infertility. However, a thorough analysis of the questionnaires made it possible to identify other clinical symptoms that occurred in 375 (20.2\%) patients. All identified patient complaints can be grouped into the following groups of symptoms: pain syndrome and menstrual irregularities. In conclusion, we analyzed the effectiveness of IVF in the studied patients (table 3). So, for 2017, 2018, 2019, into the uterine cavity 483, 639, 736 embryo transfers were carried out, of which 223, 
250, 829 clinical pregnancies were obtained, which amounted to 46\%, 39\%, 48\% of pregnancies, respectively. Thus, over 3 years, 1858 transfers were carried out, 829 pregnancies were obtained, which amounted to $44.6 \%$ of the IVF efficiency.

The results of ultrasound examination showed that 163 patients had signs of a scar consistency on the uterus. In
38 (19\%) patients, there was at least one sign of uterine scar failure. The most common sign of uterine scar inconsistency is the "niche" symptom in 16 cases $(42 \pm$ 2.67\%), every fourth one had thinning of the myometrium in the area of the scar - in 8 cases $(21 \pm 2.16 \%)$, in every sixth, the indistinctness of the endometrial contour, endometrial hypoplasia - in 5 cases $(13 \pm 2.2)$, and the rarest was the presence of cavities in the area of the scar on the uterus - in 2 cases $(5 \pm 1.85)$.

Table 4. McNemar Test

\begin{tabular}{|c|c|c|}
\hline Criteria & Criterion value & Significance level, p \\
\hline$\chi 2$ McNemar & 36.481 & $<0,001$ \\
\hline ұ2 McNemar with Yates' correction35.795 & $<0,001$ & \\
\hline$\chi^{2}$ McNemar with Edwards'correction & 35.117 & $<0,001$ \\
\hline
\end{tabular}

\section{CONCLUSION}

In our study, after confirming the inconsistency of the uterine scar, 30 patients underwent metroplasty. According to the protocol, after the surgery, the patients were prescribed contraception in order to avoid unwanted pregnancy until the full recovery of the uterine scar within 6 months. In these patients with secondary infertility, after confirmation of full recovery of the scar on the uterus, in cases of the likelihood of pregnancy, spontaneous pregnancy was expected within 6 months. In the absence of spontaneous pregnancy, they switched to the treatment of infertility using ART methods.

So, in this study, after metroplasty in one patient, pregnancy occurred spontaneously. In this patient, the duration of infertility was more than 5 years and in the anamnesis, there were more than 5 unsuccessful IVF attempts with embryo transfer into the uterine cavity. The remaining 29 patients underwent 40 transfers, of which 18 cases achieved clinical pregnancy, which amounted to an IVF efficiency of 45\%, compared to an IVF efficiency before metroplasty of 32\%. This indicator of IVF efficiency is close to the IVF efficiency in patients without a uterine scar. To assess the impact of pregravid metroplasty on the effectiveness of IVF, we performed the McNemar test (Table 4).

Table 4 shows the effect of the use of metroplasty at the pregravid stage on the effective IVF indicators with a 95\% confidence interval. That is, performing pregravid metroplasty in patients with inconsistent uterine scar will significantly increase the rate of IVF success. The results obtained contribute to the introduction of metroplasty surgery to correct the inconsistency of the uterine scar in patients when planning ART.

\section{REFERENCES}

A. Moridi, N. Roozbeh Etiology and risk factors associated with infertility // International Journal of
Women's Health and Reproduction Sciences, 2019, Vol. 7, №3, P.346-353

A.Betran, J. Ye et.al The increasing trend in Caesarean Section Rates: Global, Regional and National Estimates: 1990-2014 // PLOS One, 2016,Feb,1-12

Baron J., Weintraub A.Y., Eshkoli T., Hershkovitz R., Sheiner E. The consequences of previous uterine scar dehiscence and cesarean delivery on subsequent births // Int J GynaecolObstet, 2014, №126,P.120-122

Curtis M. Inconceivable: how barriers to infertility treatment for low-income women amount to reproductive oppression // Georgetown Journal on Poverty Law \& Policy, 2017, 25,P.323.

Davies MJ, Rumbold AR, Moore VM. Assisted reproductive technologies: a hierarchy of risks for conception, pregnancy outcomes and treatment decisions // J DevOrig Health Dis, 2017, Aug, Non8(4), №.443-447

Eniola 0.W., Adetola A.A., Abayomi B.T. A review of Female Infertility; important etiological factors and management // Journal of Microbiology and Biotechnology Research, 2017, 31, 2(3),P.379-385

ESHRE Capri Workshop Group. A prognosis-based approach to infertility: understanding the role of time // Hum Reprod, 2017, Aug 1, №32(8), №. 1556- 1559

J. Wang, M.Sauer In vitro fertilization (IVF): a review of 3 decades of clinical innovation and technological advancement // The Clin Risk Manag, 2016, Dec, 2(4),P.355-364

J. Datta, M. Palmer, C. Tanton et.al. Prevalence of infertility and help seeking among 15000 women and men // Human Reproduction, 2016, Vol.31, №9, P. 2108-2118.

J.Turk How to personalize ovarian stimulation in clinical 
practice // Ger Gynecol Assoc, 2017, Sep, 18(3),P.148153

Luke B., Stern J.E., Kotelchuck M., Declercq E.R., Anderka M., Diop H. Birth Outcomes by Infertility Treatment: Analyses of the Population-Based Cohort: Massachusetts Outcomes Study of Assisted Reproductive Technologies (MOSART) // J Reprod Med, 2016, MarApr, №61(3-4), №.114-127

Mcclintock S., Ma Z.Q., Rieger R.H. Incorrect inference in prevalence trend analysis due to misuse of the odds ratio//Ann. Epidemiol, 2016, 26(2),P.136-140 44.WenQin Lin, Ling-Nv Yao, Dong-Xue Zhang.

Patounakis, G. et al. Impact of a prior cesarean delivery on embryo transfer: a prospective study // Fertility and Sterility 2016, Volume 106 , Issue 2, 311 -316
S. Pal Prevalence of infertility and its treatment among women // US Pharm, 2018,43(9),P.14-17

Smailova, L.K., Iskakov, S.S., Tuletova, A.S.,Shegenov, G.A.Assessing the quality of life of patients with symptomatic uterine fibroid// Systematic Reviews in Pharmacy, 2020, 11(2), P. 176-182

Stemming the global caesarean section epidemic // Lancet, 2018, Vol 392, P.1279-1281

Wang Y-q. et.al. Reproductive outcomes in women with prior caesarean section undergoing In vitri Fertilization: a retrospective case-control study // J Huazhong Univ Sci Technol, 2017: 37(6),922-927

Zhang N. et.al. IN vitro fertilization-embryo transfer in patients with caesarean scar // Med Sci Monit, 2016; 22,3288-3295 